\title{
Pseudoaneurysm eroding into the duodenal bulb: an extremely rare case and treatment modality
}

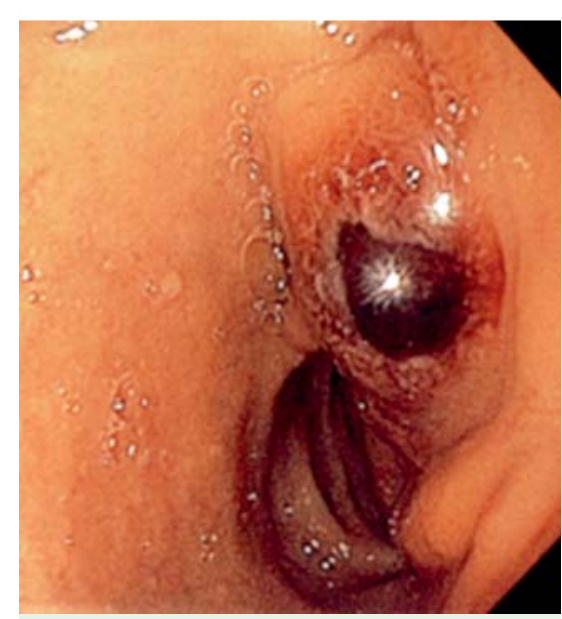

Fig. 1 Bulging lesion in the duodenal bulb region discovered on endoscopy.

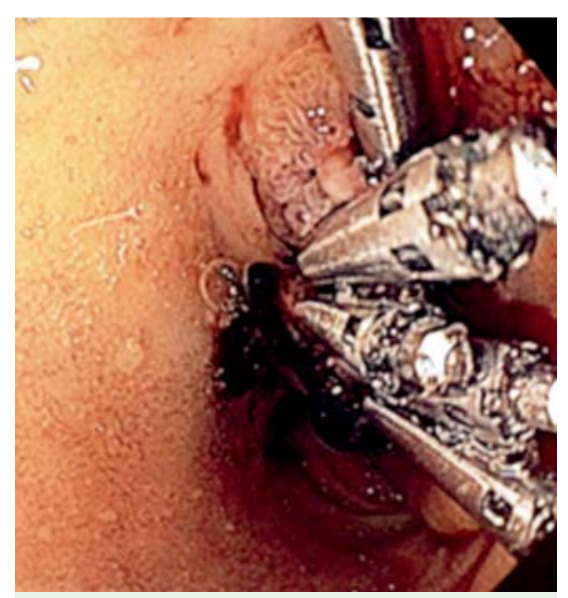

Fig. 2 Duodenal bulb lesion after endoscopic treatment with epinephrine and endoclips.

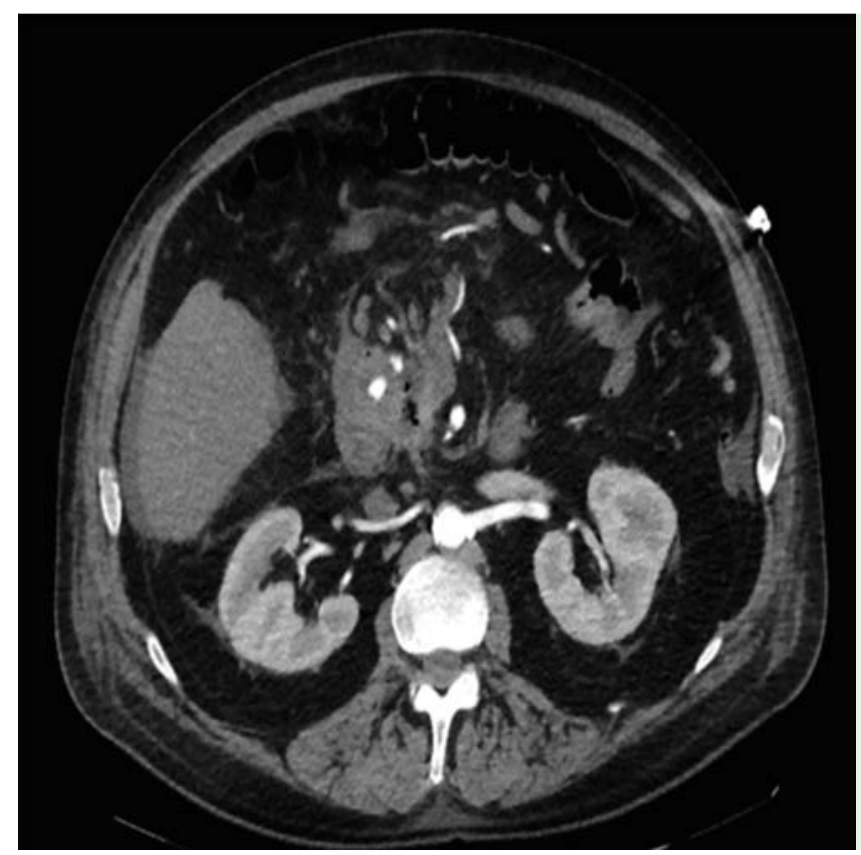

Fig. 3 Radiographic evidence of pseudoaneurysm near the duodenal bulb.

Pseudoaneurysm formation in the vessels near the pancreas is a rare complication in patients with chronic pancreatitis [1]. Treatment of bleeding pseudoaneurysms is difficult and rarely endoscopic. We present the case of a patient with chronic pancreatitis and a pseudoaneurysm eroding through the wall of the duodenal bulb, who underwent emergency endoscopic therapy for initial stabilization.
A 54-year-old man with chronic pancreatitis from alcohol was admitted to the hospital with an acute episode of pancreatitis. On hospital day 9, the patient experienced $\sim 300 \mathrm{~mL}$ of hematemesis. His vitals signs were normal except for tachycardia of 122 beats per minute. Physical examination revealed epigastric tenderness but was otherwise normal. His hemoglobin was $7.3 \mathrm{~g} / \mathrm{dL}$ (baseline $9.9 \mathrm{~g} / \mathrm{dL}$ ). He underwent endoscopy, which showed an actively bleeding, bulging $1.5-\mathrm{cm}$ red lesion with sharp borders in the duodenal bulb ( Fig.1). Epinephrine $(10 \mathrm{~mL}$ of $1: 10000)$ was injected in a four-quadrant fashion around the lesion, and five Resolution endoclips (Boston Scientific Corp., Natick, Massachusetts, USA) were placed in sequential fashion to close the lesion, resulting in successful hemostasis ( $\bullet$ Fig. 2).

Later that day, computed tomography (CT) of the abdomen was performed and showed a $1.2-\mathrm{cm}$ aneurysm formation adjacent to the duodenum ( $\bullet$ Fig. 3). Three days later, the patient underwent CT angiography, which showed endoclips on the medial aspect of the duodenal wall and contrast pooling in the pancreatic head region near the superior pancreaticoduodenal artery, with a focus within the duodenal wall, consistent with pseudoaneurysm with extravasation. He underwent angiography, which demonstrated a bleeding bilobulated pseudoaneurysm arising from the gastroduodenal artery. The pseudoaneurysm was successfully coiled. After 19 days of hospitalization, the patient was discharged with a stable hemoglobin level.

Although bleeding pseudoaneurysms are a rare complication of chronic pancreatitis, they should be considered in any patient with chronic pancreatitis who presents with upper gastrointestinal bleeding [1-3]. Radiographic intervention with coiling of the vessel is the predominate treatment, with endoscopic therapy of such lesions being extremely rare and potentially dangerous without the availability of interventional radiology $[4,5]$. In this unique case, a rare duodenal bulb pseudoaneurysm was identified on endoscopy. This pseudoaneurysm was treated endoscopically for initial stabilization (with an interventional radiologist readily available), and subsequently underwent coiling by interventional radiology.

Endoscopy_UCTN_Code_CCL_1AB_2AZ_3AD

Competing interests: None

Kristi Lopez, Dina Ahmad, Alisha Hinds, Hazem T. Hammad, Jonathan D. Godfrey, Michelle L. Matteson-Kome, Matthew L. Bechtold

Department of Internal Medicine, University of Missouri School of Medicine, Columbia, Missouri, USA 


\section{References}

1 Eckhauser FE, Stanley JC, Zelenock GB et al. Gastroduodenal and pancreaticoduodenal artery aneurysms: a complication of pancreatitis causing spontaneous gastrointestinal hemorrhage. Surgery 1980; 88: $335-$ 344

2 Chen HL, Chang WH, Shih SC et al. Ruptured pancreaticoduodenal artery pseudoaneurysm with chronic pancreatitis presenting as recurrent upper gastrointestinal bleeding. Dig Dis Sci 2007; 52: 3149-3153
3 Hepburn I, Schade R. An unusual duodenal mass with GI bleeding: gastroduodenal artery pseudoaneurysm. Am J Gastroenterol 2010; 105: S375

4 Shrikhande GV, Khan SZ, Gallagher $K$ et al. Endovascular management of superior mesenteric artery pseudoaneurysm. J Vasc Surg 2011; 53: 209-211

5 Leow VM, Siam F, Saravanan Ket al. Management of bleeding pseudoaneurysm of gastroduodenal artery secondary to chronic pancreatitis. Med J Malaysia 2013; 68: $271-272$

\section{Bibliography}

DOI http://dx.doi.org/ 10.1055/s-0034-1364944 Endoscopy 2014; 46: E124-E125

(c) Georg Thieme Verlag KG

Stuttgart · New York ISSN 0013-726X

\section{Corresponding author} Matthew L. Bechtold, MD, FACG

Division of Gastroenterology Five Hospital Drive, CE405

Columbia, MO 65212

USA

Fax: +1-573-884-4595

bechtoldm@health.missouri.edu 